\title{
This is London calling: a few recollections on the path to the 2015 ESC congress
}

\author{
$\int_{1}$ \\ Patrick W. Serruys, Editor-in-Chief
}

When I started my training in cardiology, there used to be a congress of European cardiology held every four years in one of the major countries of Western Europe. The first congress in 1952 took place in London, followed by Stockholm (1956), Rome (1960), Prague (1964) and Athens in 1968. Madrid hosted the 1972 congress and this was to be my first attendance. On a personal level, the Madrid congress gave me the opportunity to interact with my peers from far afield. But perhaps my most distinctive recollection is that many of the talks were given in the local language of the meeting, in this case Spanish. The programme in those days was developed and designed by the national society hosting the meeting. In fact, an abstract session did not exist at that time.

Paul Hugenholtz, when councillor of the ESC, devised the ultimately defining and visionary plan for European Cardiology. Not only did he set up the Working Groups and the ESC fellowship programme and propose the creation of the European Heart Journal, but he also proposed that the ESC should have its own organising committee. As a young cardiologist, I recall quite well that these proposals generated what I would now mildly define as "animated debate."

The 1976 Amsterdam congress was therefore to be built on peer-reviewed abstracts, constructed around a theme and, for the first time, using English as the language of communication. These changes were a great success. I must confess my main recollection of this particular congress was non-scientific in character, namely tasting Dutch raw herring for the first time in the exhibition hall. On a scientific level, it was also the venue of my first presentation on exercise and haemodynamic tests pre- and three months post-bypass. Let us not forget that for the Amsterdam congress we all worked very hard for its success, which meant that one had to find a monastery or campus to provide low budget accommodation for the young fellows attending the congress. There was of course neither internet nor mobile telephones, meaning that the conventional communication tool was the typewriter. That little bottle of magic correction fluid, Tipp-Ex, became, not surprisingly, very important.

Fast forwarding to 1986, the joint meeting of the Working Groups of the European Society of Cardiology and the Symposium on Ten Years Balloon Dilatation in Cardiovascular Disease took place in Santiago de Compostela, Spain. It was at this meeting that Paul Hugenholtz, now President of the ESC, suggested holding the ESC congress annually. This triggered a wave of disbelief, incomprehension and dismay. Nonetheless, the President was not to be blocked, and the General Assembly voted overwhelmingly to hold the Congress annually, starting with the Nice meeting in 1993.

Initially, those early years of the meetings of the ESC were aimed at the general cardiologist, from either an academic or a non-academic working environment, and, by definition, noninvasive imagers, as invasive imaging was not yet mainstream. However, as the surgeons had their own meeting, the ESC congress was dominated by clinical cardiology and pharmacology. Today, cardiology has changed drastically: the ESC congress is now the most dominant meeting worldwide, superseding the ACC and AHA, at least in terms of attendees. We have seen an extraordinary growth and diversity within our scientific community: the ESC congress reflects this with not only cardiologists, imaging specialists, experimental researchers, nurses, technicians, epidemiologists and bioengineers... and yes, even surgeons. It would be unfair not to mention the growing influence the EAPCI has within the ESC. With over 6,000 members, the current, elect and former presidents of the EAPCI represent with great distinction the many admirable people within our field.

In today's current economic and political arena, the dreams of European integration of Jean Monnet could be considered to be under threat. Once again this year, as we go back to London where the roots of the ESC congress were first established in 1952, we of the ESC are as strong as ever, contributing to more advancements and breakthroughs in patient care than ever previously imagined. 